\section{SOCIETY PRESIDENT BIOGRAPHIES}

\section{American Society of Neuroradiology: John Hesselink}

Dr. John Hesselink is currently Professor

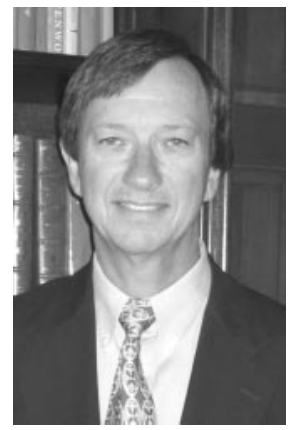
of Radiology and Neurosciences and Chief of Neuroradiology at the University of California in San Diego. He obtained his medical degree from the University of Wisconsin, where he also completed his diagnostic radiology residency. After completing his neuroradiology fellowship at Massachusetts General Hospital, he spent several years working at the Massachusetts Eye and Ear Infirmary and before that was a radiologist with the US Navy. Dr. Hesselink has been author or co-author of 155 peer-reviewed articles, 30 review articles, 5 books, and nearly 120 abstracts. His very popular textbook, Clinical Magnetic Resonance Imaging is now in its third print edition and a new e-version is also available. He is listed as an investigator or co-investigator in 20 grants. His involvement with scientific societies is extensive and he is a Past President of the Western Neuroradiological Society. Dr. Hesselink has held active roles on 10 American Society of Neuroradiology (ASNR) committees as well as being its immediate past Vice President.

\section{American Society of Functional Neuroradiology:}

\section{Timothy Roberts}

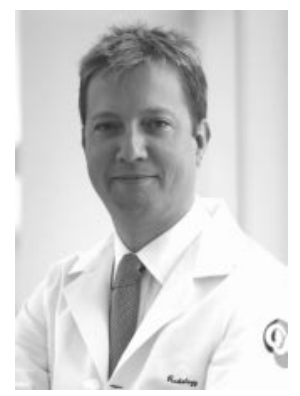

Dr. Tim Roberts is Professor of Radiology, Vice Chair for Research, and the Oberkircher Family Chair in Pediatric Radiology at the Children's Hospital of Philadelphia. He received all of his education, including his $\mathrm{PhD}$, from Cambridge University and was also a postdoctoral fellow at the University of California in San Francisco. Before his current position, he was Professor at the Department of Medical Imaging at the University of Toronto. Dr. Roberts' curriculum vitae lists 197 published articles and 57 abstracts. $\mathrm{He}$ is the author of 4 books and has served as editor for 3 other publications. Currently, he serves in the role of special consultant in physics for the American Journal of Neuroradiology (AJNR). Dr. Roberts holds 4 patents related to MR instrumentation. As a principal or co-investigator, he has participated in 24 grant-funded projects, 13 of which are current. He has been a strong supporter of ASNR and has been a member of the Scientific Program, Research, and Executive Committees. In the American Society of Functional Neuroradiology, he has served as Chair of the Research Committee, Treasurer, and

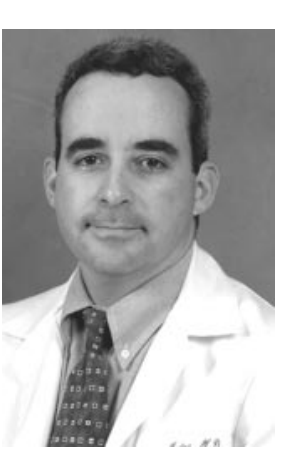

\section{American Society of Pediatric Neuroradiology: Santiago Medina}

Dr. Santiago Medina is Co-Director of Neuroradiology and Director of the International Health Outcomes, Policy, and Economics Center at Miami Children's Hospital. A native of Colombia, he completed his diagnostic radiology training at the Mallinckrodt Institute in St. Louis, and pediatric radiology and pediatric neuroradiology fellowships at Children's Hospital in Boston. During this same time, he obtained his MPH degree from the Harvard School of Public Health. Before his current position, he was Assistant Professor at the University of Cincinnati College of Medicine. Dr. Medina is the author or co-author of more than 50 articles and 19 book chapters. He has been a principal or co-investigator in 9 grants. He serves as a manuscript reviewer for AJNR and 3 other journals. At the ASNR level, Dr. Medina is a member of the Clinical Outcomes, Scholar Award, NER Foundation, and Evidence-Based Medicine committees. He has been Treasurer, Secretary, and Vice President of the American Society of Pediatric Neuroradiology.

\section{American Society of Spine Radiology: Jeffrey Stone}

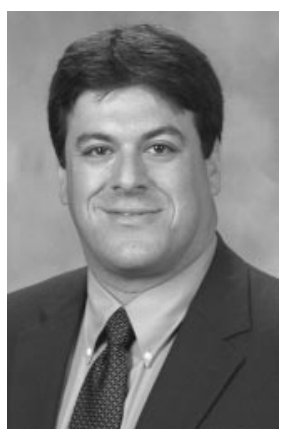

Dr. Jeff Stone is currently Associate Professor of Radiology at the Mayo Clinic in Jacksonville, Fla. He received his MD from the University of Rochester in New York. After short stints in pathology and surgery at the University of Vermont, he completed his diagnostic radiology residency at the Ohio State University Hospitals in Columbus and his neuroradiology fellowship at the University of North Carolina in Chapel Hill. Before his current position, he was Associate Professor of Radiology and Neurosurgery as well as President of the Medical Staff at the Medical College of Georgia in Augusta. He is listed in 25 peer-reviewed articles, 3 book chapters, and more than 30 abstracts as an author or co-author. Dr. Stone has been involved in 2 extramurally funded projects and holds 1 patent related to a device to treat intracranial aneurysms. His service to organized radiology has been extensive and his curriculum vitae details his involvement in 5 American College of Radiology, 8 ASNR, and 4 American Society of Interventional and Therapeutic Neuroradiology (now SNIS) committees. With regard to the American Society of Spine Radiology, he has served on 13 committees.

\section{American Society of Head and Neck Radiology: Edward Kassel}

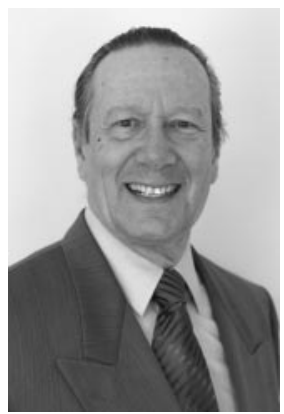

Dr. Ted Kassel is Professor of Radiology and Chief of Head and Neck Imaging at the Mount Sinai, Toronto General, Toronto Western, Princess Margaret, and Women's College Hospitals, all associated with the University of Toronto. He obtained a DDS degree from the University of Toronto before completing his MD at the University of Western Ontario. His curriculum vitae lists 15 articles, 21 book chapters, and 254 invited lectures, and he has been involved in the organization of 18 courses at national and international levels. Dr. Kassel has served on 8 different ASNR committees and held positions on nearly all committees in the American Society of Head and Neck Radiology as well as being its past Treasurer and Vice President.

DOI 10.3174/ajnr.A1647 